\title{
Malaria: how useful are clinical criteria for improving the diagnosis in a highly endemic area?
}

B. Genton ${ }^{1}$, T. Smith ${ }^{2}$, K. Baeal, A. Narara' ${ }^{1}$ F. Al-Yaman ${ }^{1}$, H.-P. Beck ${ }^{1}$, J. Hii ${ }^{1}$ and M. Alpers! ${ }^{1}$ Papua New Guinea Institute of Medical Research, P. O. Box 378, Madang, Papua New Guinea; ${ }^{2}$ Swiss Tropical Institute, Socinstrasse 57, Postfach, 4002 Basel, Switzerland

\section{Abstract}

To assess the validity of clinical criteria, we investigated 2096 outpatients diagnosed as malaria cases by nurses at a rural health subcentre in a highly endemic area of Papua New Guinea. $73 \%$ of the children $<10$ years old had a positive blood slide for any species of Plasmodium and $32 \%$ had $\geqslant 10000 \mathrm{P}$. falciparum parasites per $\mu \mathrm{L}$. For adults the frequencies were $51 \%$ and $\% \%$, respectively. Stepwise logistic regression identified spleen size, no cough, temperature, no chest indrawing, and normal stools as significant predictors for a positive blood slide in children; no cough and normal stools predicted a positive blood slide in adults. Fever, no cough, vomiting, and enlarged spleen were significant predictors for a $P$. falciparum parasitaemia $\geqslant 10000 / \mu \mathrm{L}$ in children; in adults the only predictor was vomiting. In children the association of no cough and enlarged spleen had the best predictive value for a positive blood slide, and a temperature $\geqslant 38^{\circ} \mathrm{C}$ had the best predictive value for a $P$. falciparum parasitaemia $\geqslant 10000 \mu \mathrm{L}$. In adults, no major symptom had a good predictive value for a positive blood slide but vomiting had the best predictive value for a $P$. falciparum parasitaemia $\geqslant 10000 / \mu \mathrm{L}$. When microscopy is not available, these findings can help in areas of high endemicity to determine which patients with a history of fever are most likely to have malaria and, more importantly, for which patients another diagnosis should be strongly considered.

\section{Introduction}

In endemic areas most cases of malaria are diagnosed on clinical grounds without laboratory confirmation of parasitaemia. The diagnosis is based on the presence of fever or a history of fever. Since fever is a symptom of many acute illnesses, especially in childhood, many patients treated for malaria do not have malaria. Current guidelines stress treating all cases who may have malaria with antimalarial drugs because clinical findings are insufficiently specific to identify which cases with fever or history of fever do not have malaria. In the absence of microscopy, cases with fever or a history of fever who live in malarious areas are presumed to have malaria unless symptoms or signs highly suggestive of another illness that could cause fever are present. In highly endemic areas, persons with fever should be treated for malaria even when signs of another fever-causing illness are present (WHO, 1992). Although potentially inappropriate in areas with great seasonal variation in incidence of malaria (OLIVAR et al., 1991), this strategy is safe. Nevertheless it should not prevent the need for proper training of all health workers to identify on clinical grounds true malaria cases and, more importantly, those cases with fever who may not have malaria and may require another life-saving treatment, namely antibiotics (WHO, 1986). TRAPE el al. (1985) found that clinical criteria were too non-specific to serve as useful diagnostic criteria in a semi-immune population exposed to intense and perennial transmission. So did BASSETT et al. (1991), who found no significant association between various clinical symptoms and parasitaemia in Zimbabwe. On the other hand ROUGEMONT et al. (1991) showed that fever of short duration and with no other obvious cause, occurring during the rainy season, is most likely to be malaria in children in Niger.

The aim of the present study was to identify useful clinical criteria to improve the accuracy of the diagnosis of malaria. To do so we investigated presumptive malaria cases diagnosed on clinical grounds by the staff of a rural health subcentre in the East Sepik Province of Papua New Guinea (PNG). We looked at the effect of various symptoms or signs on the occurrence of a positive blond slide and on Plasmadium falciparum densities. We then evaluated the predictive value of each of the significant clinical criteria for a positive blood slide and for a $P$. falciparum parasitaemia $\geqslant 10000 / \mu \mathrm{L}$.

\footnotetext{
*Author for correspondence.
}

Methods

Study area and population

According to the last reliable national census in 1980 , the Wosera area of the Maprik district in East Sepik Province of PNG has a popularion of 22587 persons who occupy some $800 \mathrm{~km}^{2}$. The area is highly endemic for malaria. Transmission is perennial but distribution of tainfall is somewhat seasonal, with $65 \%$ falling from November to April. Average malaria parasite prevalence is $62 \%$ in children ( $<10$ years old) and $45 \%$ in adults ( $>20$ years old), with minor seasonal fluctuations. The parasite formula is $0.55,0.25,0.2(P$. falciparum, $P$. vivax, $P$. malariae). The spleen rates are $53 \%$ in children and $7 \%$ in adults. Prevalence of reported fever at the time of the survey was $3.6 \%$ in children and $1.8 \%$ in adults (unpublished data).

\section{Subjects and methods}

As part of the Malaria Vaccine Epidemiology and Evaluation Project (ALPERS et al., 1992), we are doing passive case detection in a rural health centre in the Wosera area. Data reported here include 15 months of surveillance, from October 1990 to January 1992. Patients were selected if they were diagnosed by the nurses of the health centre, on clinical grounds only, as having malaria (first diagnosis). Usually the diagnosis was based on a history of fever without obvious symptoms or signs of another discase. These presumptive malaria cases were further investigated by a nurse or health extension officer of the PNG Institute of Medical Research. Standard data were ubtained from the clinical history, physical examination and laboratory tests. Axillary temperature was measured with an electronic thermometer. Spleen size was graded using Hackett's method. Capillary blood was sampled for thick and thin film examination. Blood films were stained with $4 \%$ Giemsa's stain and examined for 100 microscopic thick film fields under an oil immersion objective before being declared negative. Densities were recorded as the number of parasites per 200 white blood cells. Using a standard mean leucocyte count of $8000 / \mu \mathrm{L}$ (unpublished data from Wosera children), the densities were converted to the number of parasites per $\mu \mathrm{L}$ of blood (SHUTE, 1988).

\section{Data analysis}

Analysis was performed separately for children (aged $<10$ years) and adults (aged $\geqslant 15$ years) using the Statistical Analysis System (SAS, 1985) and EGRET (STATISTICS AND EPIDEMIOLOGY RESEARCH CORPORATION, 1991). 
To identify predictors for a positive blood slide we used a logistic regression model that fitted parasite positivity against each symptom and sign recorded, all of them chosen because of their high prevalence in patients attending the health centre. To identify which clinical criteria were useful for the diagnosis of clinical attack, we used (i) a linear regression model that fitted log transformed $P$. falciparum density against the same explanatory variables and (ii) a logistic regression model that fitted parasitaemia $\geqslant 10000$ parasites $/ \mu \mathrm{L}$ against the same independent variables. We retained all the significant predictors and then calculated the increase of the predictive value for a positive or negative blood slide as well as for a $P$. falciparum parasitaemia $\geqslant 10000 / \mu \mathrm{L}$ when these variables were added to the clinical assessment of the rural health centre. The following formula was used to calculate the positive predictive value of a sign or symptom: (number of cases with this symptom or sign and a positive BS blood slide [or $P$. falciparum parasitaemia $\geqslant 10000 / \mu L] /($ total number of cases with this symptom or sign?.

A threshold of 10000 parasites $/ \mu \mathrm{L}$ was chosen according to estimates of sensitivity and specificity using a logistic regression model to compare parasite densities in health centre fever cases and healthy individuals in community surveys (Tom Smith, personal communication).

\section{Results}

We recorded 17905 patients during the study period; $8732(49 \%)$ had a first diagnosis of malaria, $3825(21 \%)$ had a diagnosis of pneumonia and $2236(12 \%)$ had a diagnosis of sore or tropical ulcer. Among those with a diagnosis of malaria we fully investigated 2096 (24\%), the others having attended outside working hours or when the Institute of Medical Research staff member was absent. Tables 1 and 2 describe the demographical charac-

Table 1. Sex and age distribution of the presumptive cases of malaria studied in Papua New Guinea

\begin{tabular}{lc}
\hline & No. \\
\hline Sex & $1085(52 \%)$ \\
Female & $1007(48 \%)$ \\
Male & $4(<1 \%)$ \\
Unknown & \\
Age group & \\
$0-<1$ & $320(15 \%)$ \\
$1-<5$ & $823(39 \%)$ \\
$5-<10$ & $340(16 \%)$ \\
$10-<15$ & $123(6 \%)$ \\
$15-<20$ & $57(3 \%)$ \\
$20-<40$ & $287(14 \%)$ \\
$\geqslant 40$ & $146(7 \%)$
\end{tabular}

"Under 10 years old=children; aged 15 years and older $=$ adults
Table 2. Symptoms and signs among presumptive cases of malaria, Papua New Guinea

\begin{tabular}{|c|c|c|}
\hline & $\begin{array}{l}\text { Children }^{a} \\
\text { No. }\end{array}$ & $\begin{array}{l}\text { Adults } \\
\text { No. }\end{array}$ \\
\hline Total no. & 1483 & 490 \\
\hline \multicolumn{3}{|l|}{$\begin{array}{l}\text { Symptoms } \\
\text { Length of history (d) }\end{array}$} \\
\hline $0-3$ & $1222(82 \%)$ & $316(64 \%)$ \\
\hline $4-7$ & $226(15 \%)$ & $135(28 \%)$ \\
\hline$>7$ & $33(2 \%)$ & $39 \quad(8 \%)$ \\
\hline History of fever & $1483(100 \%)$ & $490(100 \%)$ \\
\hline Malaise & $698(47 \%)$ & $311(63 \%)$ \\
\hline Headache & $295(20 \%)$ & $359(73 \%)$ \\
\hline $\begin{array}{l}\text { Loss of appetite } \\
\text { Abnormal stools }\end{array}$ & $313(21 \%)$ & $130(27 \%)$ \\
\hline Diarrhoea & $134 \quad(9 \%)$ & $25 \quad(5 \%)$ \\
\hline Constipation & $5(<1 \%)$ & $6(1 \%)$ \\
\hline Nausea & $197(13 \%)$ & $51(10 \%)$ \\
\hline Vomiting & $253(17 \%)$ & $32(7 \%)$ \\
\hline Cough & $731 \quad(49 \%)$ & $202(41 \%)$ \\
\hline \multicolumn{3}{|l|}{ Signs } \\
\hline Temperature $\geqslant 38^{\circ} \mathrm{C}$ & $633(43 \%)$ & $93(19 \%)$ \\
\hline Consciousness & & \\
\hline Drowsy & $256 \quad(17 \%)$ & $(7 \%)$ \\
\hline Comatose & $5(<1 \%)$ & $(-)$ \\
\hline \multicolumn{3}{|c|}{ Respiratory rate (per min) } \\
\hline $10-30$ & $1098(74 \%)$ & $381(78 \%)$ \\
\hline $31-40$ & $76 \quad(5 \%)$ & $(1 \%)$ \\
\hline $41-50$ & $13(1 \%)$ & $(-)$ \\
\hline$\geq 50$ & $(1 \%)$ & $(-)$ \\
\hline Unknown & $280 \quad(19 \%)$ & $105(21 \%)$ \\
\hline Chest indrawing & $54 \quad(4 \%)$ & $14(3 \%)$ \\
\hline \multicolumn{3}{|c|}{ Spleen size (Hackett grade) } \\
\hline 0 & $574(39 \%)$ & $289(59 \%)$ \\
\hline 1 & $122(8 \%)$ & $12(2 \%)$ \\
\hline & $278 \quad(19 \%)$ & $16(3 \%)$ \\
\hline 3 & $113(8 \%)$ & $2(<1 \%)$ \\
\hline & $30,(2 \%)$ & $0 \quad(-)$ \\
\hline 5 & $4(<1 \%)$ & $2(<1 \%)$ \\
\hline Unkn & $360(24 \%)$ & $167(34 \%)$ \\
\hline
\end{tabular}

${ }^{\mathrm{a}}$ Age $<10$ years.

bAge $\geqslant 15$ years

teristics, the history and the clinical examination of these presumptive cases of malaria; Table 3 describes their parasitological findings and compares them with those from fever cases and healthy controls gathered during community surveys carried out in the same 2 years period. Of these 2096 presumptive cases of malaria, 1420 $(68 \%)$ had a positive blood slide. This means that the clinical assessment by the usual health centre staff had a predictive value for a positive blood slide (PPV) of $68 \%$ (95\% confidence interval (CI) 66-70). As expected this PPV was higher in children (73\%, CI 71-75) than in adults $(51 \%$, CI 47-56). Total parasite prevalence and $P$. falciparum prevalence were higher in the health centre presumptive cases of malaria and in the community fever cases without other major symptoms than in the healthy

Table 3. Parasitological findings in presumptive cases of malaria from the health centre and in randomly selected individuals from the community surveys in Papua New Guinea

\begin{tabular}{|c|c|c|c|c|c|c|c|c|}
\hline & \multicolumn{2}{|c|}{$\begin{array}{l}\text { Study population } \\
\text { Presumptive } \\
\text { malaria cases }\end{array}$} & \multicolumn{4}{|c|}{$\begin{array}{c}\text { Community-based surveys } \\
\text { Fever cases and } \\
\text { cough }\end{array}$} & \multicolumn{2}{|c|}{ Healthy individuals } \\
\hline & Children & Adults & Children & Adults & Children & Adults & Children & Adults \\
\hline $\begin{array}{l}\text { Total no. } \\
\text { Blood slide positive } \\
P \text {. falciparum } \\
1-999 \\
1000-4999 \\
5000-9999 \\
\geqslant 10000\end{array}$ & $\begin{array}{r}1483 \\
1077(73) \\
815(55) \\
118(8) \\
125(8) \\
92(6) \\
480(32)\end{array}$ & $\begin{array}{l}490 \\
252(51) \\
197(40) \\
89(18) \\
35 \quad(7) \\
28(6) \\
45 \quad(9)\end{array}$ & $\begin{array}{r}64 \\
49(77) \\
36(56) \\
12(19) \\
4 \quad(6) \\
3 \quad(5) \\
17(27)\end{array}$ & $\begin{array}{ll}37 & \\
16 & (43) \\
12 & (32) \\
6 & (16) \\
2 & (5) \\
1 & (3) \\
3 & (8)\end{array}$ & $\begin{array}{rr}32 & \\
19 & (59) \\
13 & (41) \\
2 & (6) \\
1 & (3) \\
3 & (9) \\
7 & (22)\end{array}$ & $\begin{array}{l}25 \\
10(38) \\
8(31) \\
7(28) \\
1 \quad(4) \\
0(-) \\
0(-)\end{array}$ & $\begin{array}{r}2228 \\
1456(65) \\
1045(47) \\
571(26) \\
288(13) \\
103 \\
83(5)\end{array}$ & $\begin{array}{l}2997 \\
1450(48) \\
821(27) \\
707(24) \\
92(3) \\
17(1) \\
5(<1)\end{array}$ \\
\hline P. vivax & $330(22)$ & $33(7)$ & $21(33)$ & 1 (3) & $9(22)$ & $3(11)$ & $522(23)$ & $374(12)$ \\
\hline P. malariae & $88(6)$ & $40 \quad(8)$ & $6(9)$ & 2 (5) & $0(-)$ & $0(-)$ & $258(12)$ & $397(13)$ \\
\hline
\end{tabular}

Children aged <10 years; aduits aged $\geqslant 15$ years; numbers in parentheses are percentages.

'Complained of fever symptoms at time of interview; 'major symptoms' =cough, abdominal pain or diarrhoea. 
controls. Community fever cases with cough had lower total parasite and $P$. falciparum prevalences (except in adults for the latter but the sample was small) than healthy controls (Table 3). Of the 2096 presumptive cases of malaria, $562(27 \%)$ had a $P$. falciparum density $\geqslant 10000 / \mu \mathrm{L}(32 \%$ [CI $30-35]$ of children and $9 \%$ [CI 712] of adults). The percentage of individuals with a $P$. falciparum density $\geqslant 10000 / \mu \mathrm{L}$ was much higher in the health centre presumptive malaria cases and community fever cases without major symptoms than in the other groups (Table 3).

The logistic regression model fitted first parasite positivity against the following explanatory variables: length of history, history of malaise, headache, loss of appetite, nausea, vomiting, abnormal stools as well as temperature, level of consciousness, respiratory rate, spleen size, cough and chest indrawing. The final model retained spleen size, no cough, temperature, no chest indrawing, and normal stools as significant predictors in children. Normal stools and no cough were predictors in adults. Table 4 summarizes the analysis of maximum likelihood

Table 4. Logistic regression analysis of predictors of the risk of a positive malaria blood slide

\begin{tabular}{lrrr}
\hline Effect & Estimate & $\begin{array}{c}\text { Standard } \\
\text { error }\end{array}$ & $P$ \\
\hline Children $^{a}$ & & & \\
Spleen size & 0.6227 & 0.0752 & $<0.0001$ \\
No cough & 0.3931 & 0.0748 & $<0.0001$ \\
Temperature & 0.2425 & 0.0630 & 0.0001 \\
No chest indrawing & 0.4683 & 0.1748 & 0.0074 \\
Abnormal stools & -0.2425 & 0.1111 & 0.0291 \\
Adults & & & \\
No cough & 0.2983 & 0.0938 & 0.0015 \\
Abnormal stools & -0.6270 & 0.2101 & 0.0028 \\
\hline
\end{tabular}

Age $<10$ years

Age $>10$ years.

estimates for these significant predictors. A bigger spleen, no cough, a higher temperature, no chest indrawing, and normal stool were associated with a positive blood slide.

The next model fitted $\log$ transformed $P$. falciparum density against the same explanatory variables as those listed above. Stepwise regression was carried out and the final model retained, in order, temperature, spleen size, cough, respiratory rate, and vomiting in children, and cough in adults. All these had values of $P \leqslant 0 \cdot 01$. Temperature and spleen size were positively correlated with $P$. falciparum density whereas respiratory rate was negatively correlated. Vomiting and no cough were associated with higher $P$. falciparum density.

The last model fitted $P$. falciparum parasitaemia $\geqslant 10000 / \mu \mathrm{I}$. against the same independent variables. Fever, no cough, vomiting and enlarged spleen were associated with a $P$. falciparum parasitaemia $\geqslant 10000 / \mu \mathrm{L}$ in children, and in adults only vomiting was associated with this density of parasitaemia (Table 5).

Table 6 shows the increase in the predictive value for a positive blood slide or for a $P$. falciparum parasitaemia $\geqslant 10000 / \mu \mathrm{L}$ when the significant predictors of these 2

Table 5. Logistic regression analysis of predictors of the risk of a $P$. falciparum parasitaemia $\geqslant 10000 / \mu \mathrm{L}$

\begin{tabular}{llll}
\hline Effect & Estimate & $\begin{array}{c}\text { Standard } \\
\text { error }\end{array}$ & $P$ \\
\hline Children & & & \\
Fever & 0.6667 & 0.0698 & $<0.0001$ \\
No cough & 0.4951 & 0.0717 & $<0.0001$ \\
Vomiting & 0.3343 & 0.0876 & 0.0001 \\
Enlarged spleen & 0.2443 & 0.0699 & 0.0005 \\
Adults & & 0.2214 & 0.0026 \\
Vomiting & 0.6666 & $0 . .219$ & \\
\hline
\end{tabular}

$\overline{\text { Aaged }}<10$ years.

${ }^{\mathrm{b}} \mathrm{Aged} \geqslant 15$ years
Table 6. Positive predictive values for $\boldsymbol{P}$. falciparum parasitaenia of different elinical criteria

\begin{tabular}{|c|c|c|}
\hline \multirow[b]{2}{*}{ Symptom or sign } & \multicolumn{2}{|c|}{ PPV $^{2}$ for parasitaemia } \\
\hline & $>0$ & $\geqslant 10000 / \mu \mathrm{L}$ \\
\hline \multicolumn{3}{|l|}{ Childsent ${ }^{\mathrm{b}}$} \\
\hline \multicolumn{3}{|l|}{ Clinical assessment } \\
\hline at rural health centre & $73(70-75)$ & $32(30.35)$ \\
\hline Vomiting & - & $44(38-51)$ \\
\hline Temperature $\geqslant 38^{\circ} \mathrm{C}$ & $79(75-82)$ & $47(43-51)$ \\
\hline No cough & $81(78-84)$ & $4 !(38-45)$ \\
\hline No other major spm.ptom & $82(78-85)$ & $39(35-3)$ \\
\hline Enlarged spleen & $86(83-89)$ & $40(36-44)$ \\
\hline With normal stools & $87(84-90)$ & $40(35-44)$ \\
\hline With no chest indrawing & $87(83-90)$ & $40(36-44)$ \\
\hline With rio cough & $90(86-93)$ & $46(41-52)$ \\
\hline \multicolumn{3}{|l|}{ Adults } \\
\hline \multicolumn{3}{|l|}{ Clinical assessment } \\
\hline at rural health centre & $51(47-56)$ & $9 \quad(7-12)$ \\
\hline Enlarged spleen & $52(34-69)$ & -6 \\
\hline No chest indrawing & $52(46-57)$ & -5 \\
\hline No cough & $58(52-63)$ & $11 \quad(8-16)$ \\
\hline Vomiting & $59(41-76)$ & $25(11-43)$ \\
\hline No other major symptom & $61(54-67)$ & $11(7-15)$ \\
\hline
\end{tabular}

aPPV=positive predicrive value $(\%)$, with $95 \%$ confidence interval in parentheses.

"Children aged $<10$ years

"No improvement of the PPV compared to the clinical assessment at the rural health centre.

Adiults aged $\geqslant 15$ years.

responses were added to the clinical assessment by the health centre staff. In children, a history of fever (necessary to be defined as a presumptive malaria case) with an enlarged spleen was a good predictor of a positive blood slide, especially if there was no respiratory and/or digestive symptom or sign associated. A history of fever with an enlarged spleen and no cough or a temperature $\geqslant 38^{\circ} \mathrm{C}$ were the best predictors of a $P$. falciparum parasitaemia $\geqslant 10000 / \mu \mathrm{L}$ (Table 6 ). In adults a history of fever with no other major symptom (no cough and no diarrhoea or constipation) was the best predictor of a positive blood shide (Table 6). Table 7 shows the predictive value for a negative blood slide (NPV) of different clinical criteria when they were used among adult cases with a history of fever. In children, none of the clinical critcria gave an NPV $\geqslant 60 \%$, so no Table is presented. In adults abnormal stools (constipation or diarrhoea) were a good predictor of a negative blood slide, especially if associated with a normal spleen.

Table 7. Predictive value for a negative malaria blood slide of different clinical criteria in adults aged $\geqslant 15$ years

\begin{tabular}{lc}
\hline Symptom or sign & Predictive valuc $(\%)^{a}$ \\
\hline Chest indrawing & $71(42-93)$ \\
Abnormal stool & $80(59-93)$ \\
Normal spleen and abnormal stools & $84(60-97)$ \\
\hline
\end{tabular}

a $95 \%$ Confidence interval in parentheses.

\section{Discussion}

There is no unambiguous criterion for the differential diagnosis of symptomatic malaria and other febrile illness in malaria endemic areas. Case definition is highly dependent on the level of malaria endemicity, use of drugs, etc. In epidemiological field studies, malaria case definition often used fever plus high parasitaemia (SNOW et al., 1988; MENON et al., 1990). Such an approach may be suitable to assess morbidity attributable to malaria in the community but is of less value in the management of patients with fever in peripheral health centres in the tropical world. Most of the health staff, indeed, have no access to laboratory facilities and must therefore rely on the history and clinical examination only to diagnose a true malaria attack. Assuming the sensitivity of the clinical diagnosis of malaria by the health staff to be very high and the specificity to be low, we chose to investigate only 
those cases diagnosed as malaria by the health centre staff. As we were interested to improve the diagnosis of individual episodes of malaria, we focused our analysis on the assessment of the predictive values. Clinical evaluation by the health centre staff gave a predictive value for a positive blood slide of $73 \%$ in children and $51 \%$ in adults. Clinical assessment of febrile children by a rural medical aide in Tanzania gave a similar value (ROOTH \& BJÖRKMAN, 1992). The difference between the predictive value in children and adults is very likely to be due to the difference of parasite prevalence between these 2 groups; $65 \%$ of the healthy children were parasitaemic and only $48 \%$ of healthy adults in concurrent community-based cross-sectional surveys. The small difference in blood slide positivity between presumptive cases of malaria and the random survey shows by itself that the presence of parasitaemia is not a useful indicator of morbidity and does not really help to diagnose a malaria attack. However, as we have shown that coincidental infection tends to suppress parasitaemia, comparison between parasite prevalence in presumptive malaria cases and healthy controls may not be appropriate. Clinical assessment by the health centre staff gave a predictive value for a parasitaemia $\geqslant 10000 / \mu \mathrm{L}$ of $32 \%$ in children and $9 \%$ in adults. Again, this should be related to the frequencies of $P$. falciparum parasitaemia $\geqslant 10000 / \mathrm{uL}$ among community controls, which were $3.7 \%$ and $0.2 \%$ respectively.

Thus, the clinical assessment by the health centre staff significantly increased the probability that a patient had high parasitaemia, although the proportion of those with a $P$. falciparum parasitaemia $\geqslant 10000 / \mu \mathrm{L}$ was still quite low. The rather poor performance of the clinical evaluation in detecting high parasitaemia may be explained by the fact that many febrile patients are classified as "malaria' because they do not have specific symptoms or signs for another disease. This is especially so when they attend the health centre early in the course of the disease.

It is commonly agreed that, in highly endemic areas with perennial transmission, malaria is probable when there is a history of fever with no other major symptom. Our findings confirm this statement. Our best predictors from the history were primarily negative. It is also well known that digestive manifestations can occur during a malaria attack but we would not really expect vomiting to be a good predictor for a $P$. falciparum parasitaemia $\geqslant 10000 /$ $u \mathrm{~L}$. This finding is in agreement with several studies that report a high frequency of vomiting, especially in adult malaria (KODJOH, 1990; LuBALO \& MABUWA, 1990; CARME et al., 1991; SINGH et al., 1992), and is important for decision-making as this symptom may be unusually acute and be mistaken for a possiblc surgical emergency.

The clinical examination did not help with the diagnosis of malaria in adults. On the other hand, in children, an enlarged spleen was a good predictor for a positive blood slide. The high spleen rate in community controls (53\%) has again to be taken into account in the assessment of the predictive value. A temperature $\geqslant 38^{\circ} \mathrm{C}$ was a good indicator of a $P$. falciparum parasitaemia $\geqslant 10000 / \mu \mathrm{L}$ in children. Such an association was not true in adults; they were even less likely to have a positive blood slide when febrile. This finding may be related to the development of 'anti-toxin' immunity that renders the adults less susceptible to the effect of pyrogens released by the parasites (reviewed by CLARK \& Chaudhri, 1989; Peterson et al., 1991).

An assessment of the negative predictive value (NPV) was made only for the blood slide positivity rate. We could not identify a symptom or sign with a good NPV in children due to the low prevalence of negative blood slides in this group. This was rather disappointing, as negative predictors would be more helpful than positive predictors in an area where antimalarial drugs are given to everybody. Negative predictors would suggest the need for another treatment. In adults, diarrhoea was a good predictor for a negative blood slide, especially if associated with a normal spleen. It was, however, of marginal interest as the prevalence of diarrhoea was low in this community.

One can argue that the evaluation of test criteria using predictive values is a useless exercise as any improvement of the predictive value is achieved at the cost of lower sensitivity. This is correct when the objective is to evaluate test criteria for screening in the community or for changing treatment policies. Our study was not designed to give a definite clinical algorithm but to help health workers to distinguish febrile episodes probably due to malaria from febrile episodes probably not due to malaria. Indeed, in highly endemic areas, the question for the health worker is not 'should I give antimalarial drugs to this febrile patient?' but 'should I give antimalarials plus another treatment to this febrile patient?'. Although the findings of the present study might not be appropriate in all areas, for example where diarrhoea is common, they should assist health workers in making their clinical judgement in highly endemic areas.

\section{Acknowledgments}

We are grateful to the residents of the Wosera area for their co-operation. We thank the staff of Kunjingini Health Centre for their collaboration and the Institute of Medical Research microscopists for examining the slides. This work was part of the Malaria Vaceine Epidemiology and Evaluation Project funded by the United States Agency for International Development, no. 9365967.89 .

\section{References}

Alpers, M. P., Al-Yaman, F., Beck, H.-P., Bhatia, K., Hii, J., Lewis, D., Paru, R. \& Smith, T. (1992). Malaria vaccine epidemiology and evaluation project of Papua New Guinea: rationale and baseline studies. Papua New Guinea Medical foumal, 35, 285-297.

Bassett, M. T., Taylor, P., Bvirakare, J., Chiteka, F. \& Govere, E. (1991). Clinical diagnosis of malaria: can we improve? Journal of Tropical Medicine and Hygiente, 94, 65-69.

Carme, B., Dhellot, H., Senga, J., Nzingoula, S., Plassard, H., Obengui Ekutudzola, J. R. \& Mblawa, C. G. (1991). Présentation clinique des accès palutres non perniçieux hospitalisés à Brazzaville (Congo) en 1989. Bulletin de la Société de Pathologte Exotique, 84, 266-272.

Clark, I. A. \& Chaudhri, G. (1989). Relationships between inflammation and immunopathology of malaria. In: Malaria: Host Responses to Infection, Stevenson, M. M. (editor). Boca Raton: CRC Press, pp. 127-146.

Kadjoh, N. (1990). Manifestations digestives au cours de paludisme de l'adulte en zone endemique. Annales de Gastroentérologie et Hépatologie, 26, 279-284.

Lubalo, S. K. \& Mabuwa, C. (1990). Complications of seasonal adult malaria at a central hospital. Central African fournal of Medicine, 36, 268-273.

Menon, A., Snow, R. W., Byass, P., Greenwood, B. M. Hayes, R. J. \& N'Jie, A. B. H. N. (1990). Sustained protection against mortality and morbidity from malaria in rural Gambian children by chemoprophylaxis given by village health workers. Transactions of the Royal Soctety of Tropical Medicine and Hygime, 84, 768-772.

Olivar, M., Develoux, M., Abari, A. C. \& Loutan, L. (1991). Presumptive diagnosis of malaria results in a significant risk of mistreatment of children in urban Sahel. Transactions of the Royal Society of Tropical Medicine and Hygiene, 85, 729-730.

Petersen, E., Hogh, B., Marbiah, N. T., David, K. \& Hanson, A. P. (1991). Development of immunity against Plasmoditum falciparum malaria: clinical and parasitulogical immunity cannot be separated. Foumal of Infectious Diseases, 164, 949-953.

Rooth, I. \& Björkman, A. (1992). Fever episodes in a holoendemic malaria area of Tanzania; parasitological and clinical findings and diagnostic aspects related to malaria. Transactions of the Royal Sociery of Tropical Medicine and Hygiene, 86 , $479-482$.

Rougemont, A., Breslow, N., Brenner, E., Moret, A. L., Dumbo, O., Dolo, A., Soula, G. \& Perrin, L. (1991). Epidemiological basis for clinical diagnosis of childhood malaria in endernic zone in West Africa. Lancet, 338, 1292-1295.

SAS (1985), SAS User's Guide, version 5. Cary, North Carolina: SAS Institute Inc.

Shute, G. T. (1988). The microscopic diagnosis of malarin. In: Malaria, vol.1, Wernsdorfer, W. H. \& McGregor, I. (edj- 
tors). Edinburgh: Churchill Livingstone, pp. 781-814.

Singh, G. P. Misra, S. P., Narasimham, M. V. \& Kalra, N. L. (1992). Management of admitted malaria cases in four major hospitals of Delhi: a case study. Indian foumal of Malariology, $29,95-102$.

Snow, R. W., Lindsay, S. W., Hayes, R. I. \& Greenwood, B. M. (1988). Permethrin-treated bed nets (mosquito nets) prevent malaria in Gambian children. Transactions of the Royal Soctety of Tropical Medicine and Hygiene, 82, 838-842.

Statistics and Epidemiology Research Corporation (1991). EGRET: User's Mantul. Seattle: Statistics and Epidemiology Research Corporation.

Trape, J. F., Peelman, P. \& Morault-Peclman, B. (1985). Critcria for diagnosing clinical malaria among a semi-immune population exposed to intense and perennial transmission. Transactions of the Roval Society of Tropical Medicine and Hygiene, 79, 435-442.

WHO (1986). Expert Committee on Malaria, I8th Report. Geneva: World Health Organization, Technical Report Series, no. 735 .

WHO (1992). The overlap in the clinical presentation and treatment of malaria and pnetumonia in children: report of a meeting, Geneva, 8 April 1991. Geneva: World Health Organization, mimeographed document no. WHO/MAL/92.1065.

Received 27 September 1993; revised 23 November 1993; accepted for publication 6 January 1994

\section{Short Report}

\section{The effect of BCG vaccination on the leishmanin skin test}

Mohammad Abdur Rab ${ }^{1}$ and David A. Evans ${ }^{2 *} \overline{{ }^{*}}$ National Institute of Health, Islamabad, Pakistan; 2Department of Medical Parasitology, London School of Hygiene and Tropical Medicine, Keppel Street, London, WCIE $7 H T, U K$

The first outbreaks of visceral leishmaniasis (VL) in Pakistan were in the north-east of Baltistan, in isolated valleys in the western Himalayas and the Karkurum mountains (AHMED \& BuRNEY, 1962). Sporadic occurrence of VL followed in the region for at least 2 decades, after which no further case has been reported (BURNEY et

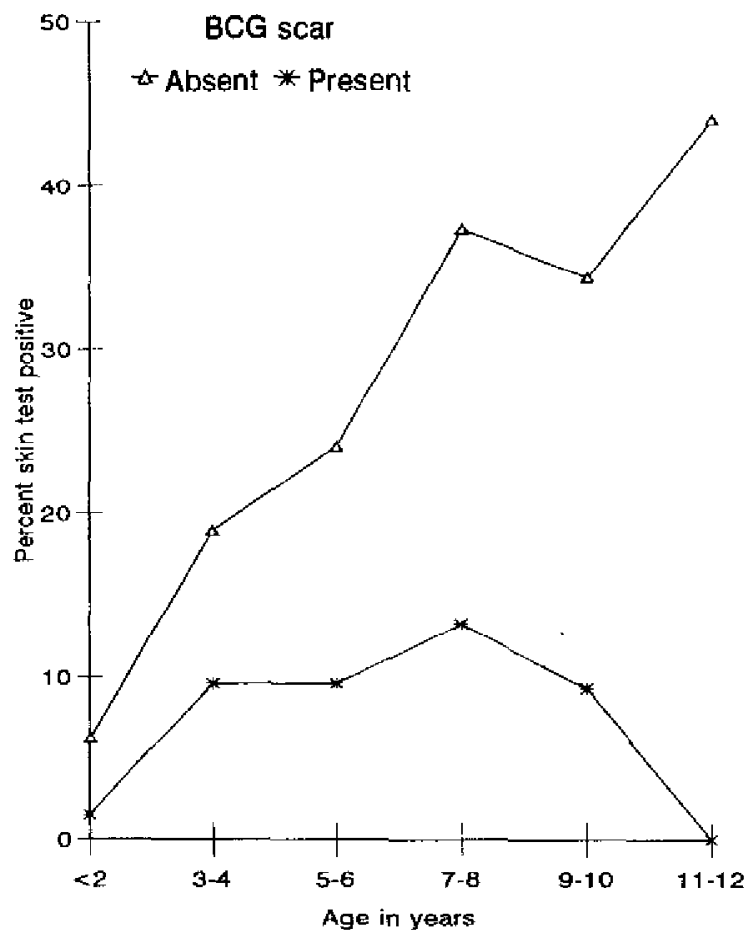

Fig. 1. The effect of prior BCG vaccination on the leishmanin skin test in children aged 12 years or less. The numbers tested, for those with and without a $B C G$ scar respectively, wete 67 and 65 at age $<2$ years, 94 and 106 at $3-4$ years, 83 and 121 at 5-6 years, 68 and 118 at $7-8$ years, 43 and 70 at $9-10$ years, and 35 and 75 at $11-12$ years.

\footnotetext{
*Author for correspondence.
}

al., 1981). In the $1980 \mathrm{~s}$ cases of VL were seen for the first time in Chilas District of the Northern Areas (NA), in the sub-Himalayan region of Azad Jammu and Kashmir (AJK) and the neighbouring areas of North-West Frontier Province (NWFP) and Punjab Province ( $S A$. LEEM et al., 1986). The disease occurs mainly in children, is caused by Leishmania infantum (see RAB et al., 1989), and remains endemic in these regions.

As part of a study to determine the prevalence of $\mathrm{VL}$ in some of the endemic foci of NA and AKJ, the effect of prior BCG (bacillus Calmette-Guérin) vaccination on the response to leishmanin was examined in 945 children under the age of 12 years. The children were part of a larger cross sectional study in which a random sample of the population was drawn from 14 villages. Evidence of $B C G$ vaccination, the presence or absence of a scar, was sought, and in 390 children $(41 \cdot 3 \%)$ BCG vaccination was confirmed. Phenol-killed promastigotes of $L$. infantum MHOM/TN/80/IPT l were used as leishmanin antigen, prepared at the London School of Hygiene and Tropical Medicine, London, UK, using the method de-

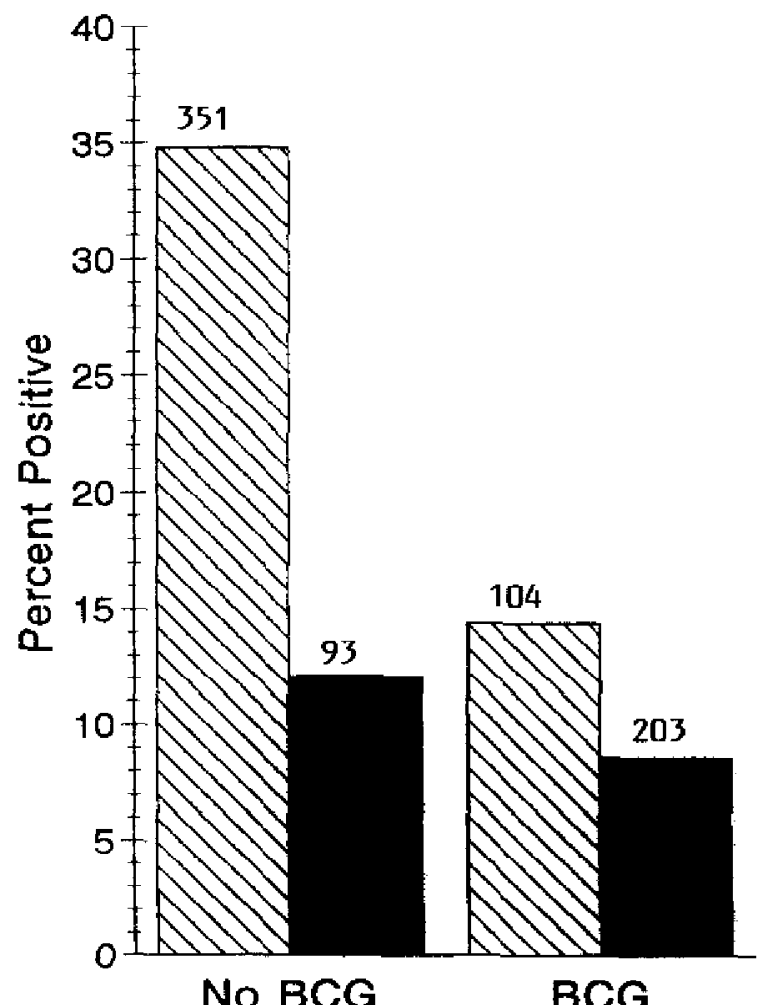

Fig. 2. Comparison of leishmanin skin test response in children aged under 12 years, in Chilas (hatched bars) and AJK (solid bars). The numbers above the columns are the numbers of children tested. 